the variable nature of this layer on days before and after the eclipse and because the effect which was found was not coincident with the solar effect but was considerably later.

The present measurements seem to give a more definite correlation between the eclipse occurrence and the time of decrease in ionic density of the $F_{2}$ region, in that the decrease began within a few minutes after the first contact, with a minimum shortly after the maximum of the eclipse and a recovery to a more or less constant higher value a few minutes after the last contact. At no time during these measurements on the eclipse day or the days after was there any other variation of a comparable magnitude.

It must be remembered, however, that the $F_{2}$ region is of a very variable nature and it will take many eclipses before we are absolutely sure of the effect produced upon it.

These results, together with the results of the August 31, 1932, eclipse, indicate that ultra-violet light is an important ionising agency in the $E, M$, $F_{1}$ and $F_{2}$ regions.

Bell Telephone Laboratories, J. P. Schafer. W. M. GOODALL. Deal, N.J. Feb. 6.

1 This is the intermediate region, see Schafer and Goodall, NATURE, 131, $804 ; 1933$.

'Kirby, Berkner, Gilliland and Norton, Proc. I.R.E., Feb., 1934 Henderson, Canadian $J$. Research, January, 1933. Schafer and Goodall, Science, Nov. 11, 1932.

\section{Occurrence of Zoosporangia in Spongospora subterranea, (Wallroth) Lagerheim}

Although powdery scab disease of potatoes has been known and studied for nearly one hundred years, zoosporangia have never been described in the life-history of the causal organism, Spongospora

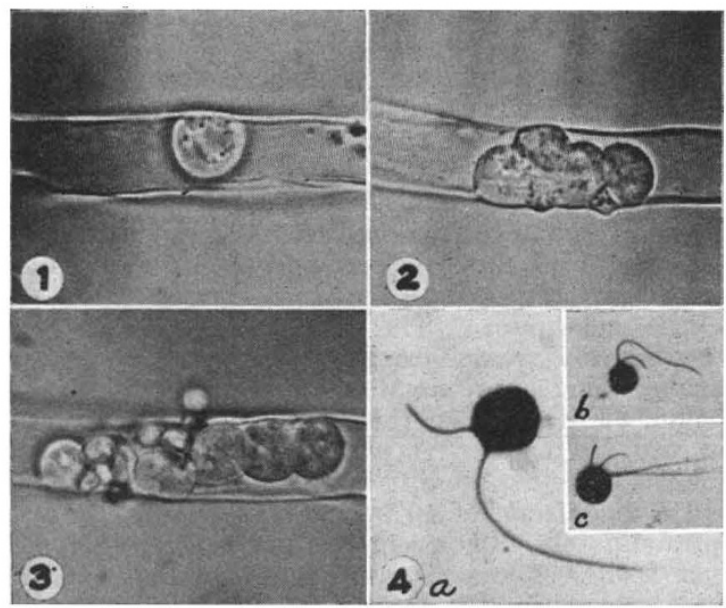

Figs. 1-4. Spongospora subterranea. Fig. 1. Early stage in zoosporangial formation in root hair of tomato; $\times 1,000$, Fig. 2. Zoospore discharge about to begin. Note swelling on cell-wall of root hair; $\times 1,000$. Fig. 3. Zoospores being dis$b, \times 1,000 ; c$ (zygote ?) $\times 1,000$.

subterranea. Zoosporangia have, however, been observed in other genera of the Plasmodiophorales by Cook $^{1}$ and by $\mathrm{me}^{2}$. It therefore seemed probable that they might be found in Spongospora, especially if microscopic examinations of the roots of the host were made early in the course of the disease.

Tomato and potato seedlings were planted in soil which, after steam sterilisation, had been inoculated with spore balls from diseased tubers. At $65^{\circ} \mathrm{F}$. heavy infection was obtained in two weeks in the root hairs of both hosts. All stages of development from amœbæ which had just penetrated the host to mature zoosporangia were observed. Sometimes single zoosporangia were present in root hairs or epidermal root cells (Fig. 1). More often they lay in rows or clusters (Figs. 2 and 3 ), sometimes of a dozen or more, nearly filling the host cell. Development of a single zoosporangium to form a cluster appears to take place by a process of budding.

Zoospore discharge is not accomplished through exit tubes but through a rupture in the host cell-wall resulting from pressure from a swelling which develops at one point in the zoosporangium (Fig. 2).

Zoospores from zoosporangia are similar to swarmspores from germinating spore balls in size, shape, ciliation and manner of swimming. It is of interest to note that the occurrence of two cilia of unequal length confirms former observations on ciliation of zoospores in the Plasmodiophorales ${ }^{3}$. The presence of occasional binucleate spores with four cilia (Fig. 4c) suggests a possible fusion of gametes. Further studies are being made on the origin and subsequent development of these.

National Research Laboratories, Ottawa, Canada.

${ }^{1}$ Trans. British Myc. Soc., 11, 196-213; 1926 ; and Proc. Roy. Soc., B, 218, 283-314; 1930 .

Phytopathology, 23, 20; 1933 (Abstract).

NATURE, 133, 534; 1934.

\section{An Abnormality in the Boyau Calicial (Female Accessory Glands) of the Desert Locust, Schistocerca gregaria, Forsk.}

WHILE dissecting out the ovaries of the desert locust, Schistocerca gregaria, some time ago, I came across an abnormality in the accessory glands which is worth recording.

Normally, the boyau calicial in Schistocerca gregaria, as in all other Acridiidæ (vide Fedorov ${ }^{1}$, Fenard ${ }^{2}$ and Uvarov $^{3}$ ), consist of a pair of unbranched forward prolongations of the two egg-calyces anterior to the base of the first ovariole. Each boyau is a much-coiled structure and usually bends inwards to touch its fellow of the other side. As Fenard ${ }^{2}$ had observed long ago, these glands acquire their maximum development shortly before oviposition and "secrete a substance which is destined to be extruded at the same time as the eggs". This substance is the material which forms the basis of the egg-pod, and also forms a protective 'froth' over the eggs. In the uncoiled condition the glands are about $3 \mathrm{~mm}$. long in a freshly emerged female and 8-12 $\mathrm{mm}$. long in a female about to lay eggs.

The abnormality of the glands in the present case consists in the fact that the right gland shows an extra diverticulum arising from its outer side at a point about one third the length of the gland from its anterior tip. It reaches forward beyond the latter. The length of the main gland is about $4.8 \mathrm{~mm}$. and that of the diverticulum $3 \mathrm{~mm}$. The latter has exactly the same appearance as the main gland and 